特＼cjkstart集 「血管内手術の現状と今後の展望」

\title{
腹部内藏動脈瘤，腎動脈狭窄に対する血管内手術
}

\author{
五島 雅和 塩野 元美 \\ 日本大学医学部外科学系心藏血管・呼吸器・総合外科学分野
}

\section{Endovascular Treatment for Visceral Artery Aneurysms and Renal Artery Stenosis}

Masakazu Goshima and Motomi SHIONo

\author{
Division of Cardiovascular, Respiratory and General Surgery, Department of Surgery, \\ Nihon University School of Medicine
}

\begin{abstract}
Endovascular treatments for visceral artery aneurysms (VAAs) and renal artery stenosis (RAS) have increased rapidly in recent years and endovascular approaches have supplanted surgical approaches for revascularization. A number of endovascular treatment studies have reported prevention of VAA rupture and clinical benefit for patients with RAS. This review summarizes the current status of endovascular treatment of VAAs and RAS.
\end{abstract}

Key words: visceral artery aneurysm, splanchnic artery aneurysm, renal artery stenosis, endovascular surgery, endovascular treatment 腹部内臓動脈瘤, 腎動脈狭窄, 血管内治療, 血管内手術

(J. Nihon Univ. Med. Ass., 2011; 70 (1): 18-22)

はじめに

腹部内藏動脈瘤, 腎動脈狭窄に対する血管内治療は近 年急速に増加し, 外科治療に変わるものとなった . 血管 内治療によって内臟動脈瘤破裂の阻止や腎動脈狭窄の臨 床上の改善の報告は多くあり，本稿では腹部内蔵動脈瘤 と腎動脈狭窄に対する血管内治療の現状について概説す る。

\section{I. 腹部内臟動脈瘤}

腹部内藏動脈瘤はまれな疾患であり，光の発生頻度は 0.01-2\%と言われている1). 近年，画像診断の進歩により 健診や他疾患精査中に偶発的に無症候性の内藏動脈瘤が 発見される頻度か増加傾向にある . 過去の報告において 内藏動脈瘤は30-40\%の破裂頻度があり，破裂した際は 致死率が高い (25-70\%) とされているため ${ }^{2)}$ ，本疾患に対 しては早期発見早期治療が重要である。

腹部内藏動脈瘤で最も頻度が高いのは脾動脈であり約 60-80\%を占めるとされており，以下，肝動脈 20\%，上 腸間膜動脈 (SMA) 5.5\%，腹腔動脈 4\%，胃十二指腸動脈 と产の分枝 6\%，下腸間膜動脈 (IMA) 1\%未満となってい る3).

瘤の形態としては紡鍾状，囊状があり，また動脈壁の 3 層構造の保たれている真性瘤と，血管壁に亀裂を生じ 周囲に血腫を伴う仮性瘤に分類される . 真性瘤の成因は ほとんどか変性によるもので, 動脈硬化性, 線維筋性異 形成，膠原病などがあり (4)，仮性瘤の成因は，外傷，炎 症，感染，医原性などである。

腹部内藏動脈瘤は产の発生部位により異なった特徵を
示す．以下，代表的な内藏動脈瘤について述べる．

最も頻度の高い脾動脈瘤は, 弚の成因として, 娃娠, 門脈圧亢進症, 膵炎, 膵蔵手術後などとの関連性か指摘 されている . 特に娃娠はエストロゲン分泌の変動による 血管壁弾性纎維の消失や, 腹腔内圧の上昇から脾動脈血 流の増加などが影響していると考えられている5) . 娃娠 中に脾動脈瘤力破裂した際は，妊婦死亡率 70\%，胎児死 亡率 $90 \%$ との報告がある ${ }^{6}$.

肝動脈瘤は, 近年の経皮的肝穿刺や経皮的胆道ドレ ナージの増加による医原性の仮性動脈瘤の報告が多い傾 向にある. 乥して最近の肝動脈㽣の $50 \%$ は肝実質内の仮 性動脈瘤と言われている7)。これらの瘤は塞栓術で比較 的容易に対処可能である。一方, 肝外動脈瘤は部位によ り対処が異なる．総肝動脈瘤に塞栓術を施行した場合 は, 胃十二指腸動脈からの側副血行で肝血流が保たれて いれば血行再建は不要であるが, 固有肝動脈瘤の場合は 側副血行か限られているため, 血行再建が必要となるこ とが多い . covered stent は瘤を閉鎖血栓化すると同時に 末梢の肝血流も保つことが可能である.

上腸間膜動脈瘤は他の動脈瘤に比へ，感染性動脈瘤の 頻度が高い $(33-66 \%)^{8,9)}$. また近年，分節性中膜融解症 (segmental arterial mediolysis: SAM) に起因する報告例が 増加してきている ${ }^{10)}$. 瘤は中枢側に生じることが多く， コイル塞栓術や瘤切除, 結紮術を行った場合, 腸管虚血 を来さぬよう血行再建を同時に行うことを常に考慮する 必要がある.

腹腔動脈瘤は胃十二指腸動脈を介した側副血行に問題 がなければ，血行再建なしにコイル塞栓術や瘤切除，結 紮術が可能である. 


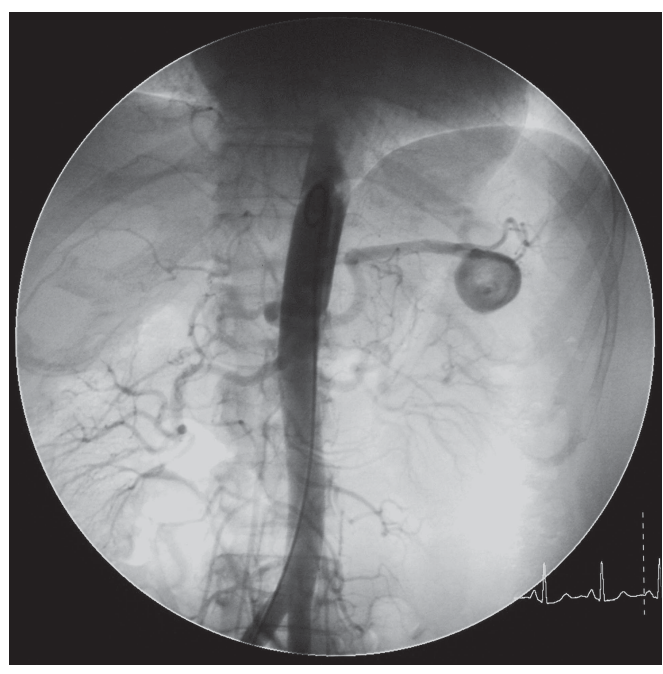

A

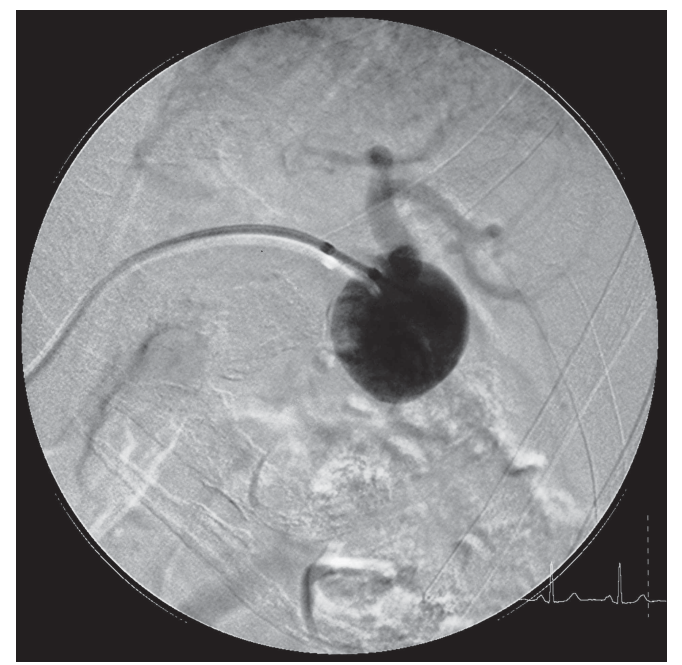

B

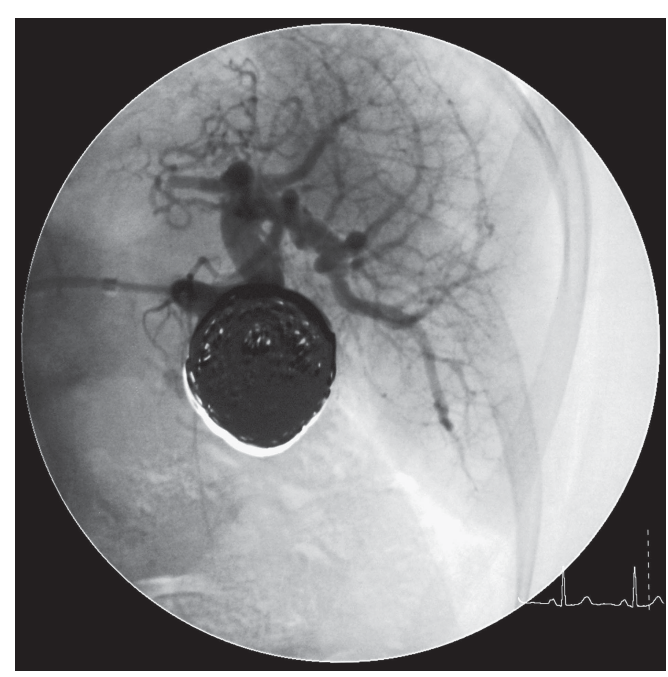

C

Fig. 1 A: Aortography reveals a saccular aneurysm of the distal splenic artery. B: Selective angiography shows a saccular aneurysm with a narrow neck. $\mathbf{C}$ : Completion angiography after coil embolization.
胃十二指腸動脈瘤と脺十二指腸動脈瘤は脺炎に伴い動 脈壁か破綻し仮性動脈瘤を形成することが多い11)。一般 的にこの領域の動脈瘤は膵炎や術後の影響が強いため， 外科的アプローチが困難である場合がほとんどであり血 管内治療が有用である .

\section{治療適応}

内藏動脈瘤の治療適応について, 確立されだ指針はな いのか現状であるが，破裂や症候性動脈瘤，仮性瘤，急 速に瘤径が拡大するもの, 瘤径が $2 \mathrm{~cm}$ 以上のものは治 療適応とされている12). ACC/AHA のガイドライン13)で は, 瘤径が $2 \mathrm{~cm}$ 以上で, 現在妊娠していない出産可能 年齢の女性および肝移植を予定している男女に対して治 療適応であるとしている (クラス I の勧告) .

治療法

内藏動脈瘤の治療は瘤の存在部位や形状，全身状態な どにより外科的治療か血管内治療か決定される . 過去に おいては手術が治療の主流であったが, 手術死亡率と合 併症の頻度が高いため ${ }^{12)}$, 今や血管内治療が兴の低侵襲 性，良好な治療成績などから第一選択となっている．治 療の目標は瘤への中枢側，末梢側からの血流を遮断し圧 を取り除いて瘤の破裂を予防することである．しかし瘤 の存在部位によっては末梢血流の温存が必要な場合もあ り，種々の工夫を要す。

血管内治療の方法には金属コイル塞栓術を中心に以下 のような手技がある．1) 瘤内 packing：動脈瘤内に金属 コイルなどの塞栓物質を挿入し内腔を閉鎖する . narrow neckの真性囊状瘤に有効で，末梢の血流は温存される (Fig. 1A, B, C) . 2) PDE (proximal and distal embolization)：瘤の遠位側と近位側を金属コイルで塞栓する．仮 性動脈瘤に有効．3) 瘤内 packing + PDE : 紡錘状動脈瘤 の TAE でよく用いられる．2)，3）の手技はいずれも末 梢の血流は得られないため藏器虚血に注意が必要であ る .4) PE (proximal embolization)：通常中枢側のみの塞 栓術は末梢側からの血流により瘤の再疎通の危険がある が, 実質藏器内の終末動脈の瘤では有効．光の他に末梢 側の血流を温存する手技としては，5) bear metal stent 留 置 + packing: wide neck の囊状瘤に対して stent 留置後, ステントの間隙からマイクロカテーテルで瘤内 packing を行う．6) covered stent 留置 ${ }^{14)}$ ：人工血管を被覆したス テントを使用 . 瘤の形態に左右されない. 特に covered stent は瘤の血栓化と末梢の血流の温存が同時に得られる 有用な方法であるが, 残念ながら本邦では未だ保険適応 のある入手可能な covered stent はない .

治療成績

血管内治療の成績は諸家らにより良好な成功率 (89.7$100 \%)$ か報告されており，満足すべき結果が得られてい る $^{15,16)}$.

治療後はいずれの血管内治療手技においても，慎重な 経過観察は必要である.合併症として, 発熱, 疼痛, 一過 
性の肝膵酵素上昇といつた post embolization syndrome ${ }^{17)}$, コイルや covered stent の逸脱 ${ }^{18,19)}$, 塞栓による末梢側の 血栓閉塞や臟器虚血症状 ${ }^{20)}$, 膿瘍形成, 瘤自体やアクセ スルートの血管損傷，また晚期に再灌流による瘤の拡大 や , covered stentの閉塞などを認めるケースも少なから ず存在する .

今後の展望

内藏動脈瘤に対する血管内治療は, 今後デバイスの更 なる進歩により今以上に普及して行くことが予想される が, 解剖学的に血管内治療が適さないような症例や，血 管内治療不成功例には手術か唯一の治療法となることも ある．よって種々の治療法を熟知し，高度な技術を習得 することが重要である．

\section{II. 腎動脈狭窄症}

近年, 食生活の欧米化による生活習慣病や高齢化社会 の到来により動脈硬化性疾患の増加が問題となり，腎動 脈狭窄に対する関心も以前に増して集まるようになって いる

腎動脈狭窄は二次性高血圧の主たる原因として知られ ており，弚の頻度は $5 \%$ とされている．腎動脈狭窄の原 因としては，粥状動脈硬化性が $90 \%$ を占め，以下若年女 性に多く見られる線維筋性異形成 (fibromuscular dysplasia: FMD) が続き, 兴の他大動脈解離, 高安病などがあ $ろ^{21)}$.

弹状動脈硬化性腎動脈狭窄 (atherosclerotic renal artery stenosis: ARAS) は腎血流量の低下や粥腫塞栓などによ り，腎血管性高血圧の原因となるばかりでなく虚血性腎 症による腎機能障害をもたらす．さらに最近では心不全 や，狭心症との関連が指摘され，心血管イベントや生命 予後とも関わるとされているため22,23), 兴の治療意義は 高いと考えられている .

治療適応

腎動脈狭窄における血管内治療の適応は, 2005 年の

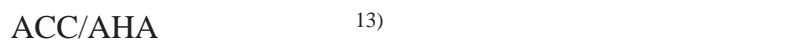
うっ血性心不全または突然の肺水腫 (クラス I の勧告)， 難治性高血圧, 悪性高血圧, 萎縮腎を伴った高血圧, 薬 剂不耐性高血圧, 両側性の腎動脈狭窄, 機能している単 腎の腎動脈狭窄で進行性の腎機能障害を認めるもの(以 上クラス IIa の勧告)，などがあげられている .

治療法・治療成績

腎動脈狭窄に対する血管内治療はバルーン血管拡張術 に始まったが, 現在 ARAS の治療の主体はステント留置 が基本である (Fig. 2A, B, C) . バルーン拡張とステント を比較した報告では，再狭窄率は前者で $48 \%$ ，後者で $14 \%$ とステント留置の優位性を示し光の妥当性を認めて いる24) . ステント留置により多くは高血圧の改善傾向が 認められるが , 根治することは極めてまれで , 弚の根治 率は $10 \%$ 未満である ${ }^{25,26)}$. 光の理由は本態性高血圧や腎

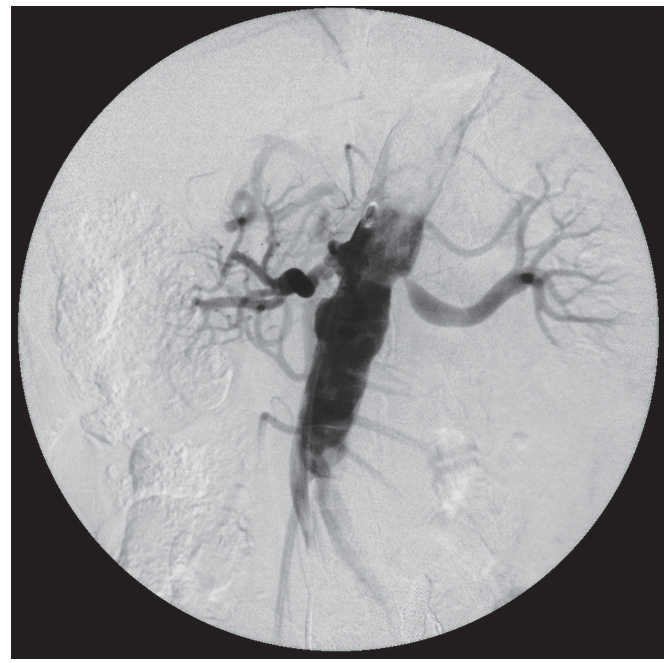

A

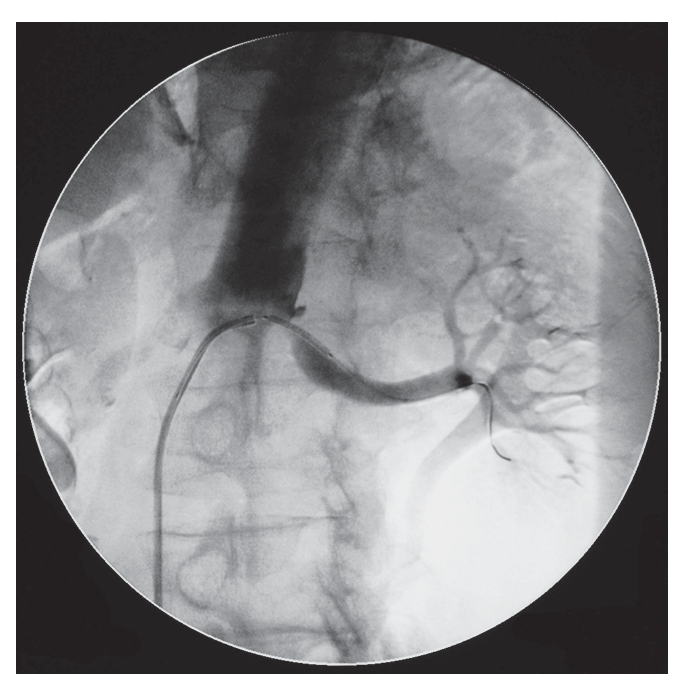

B

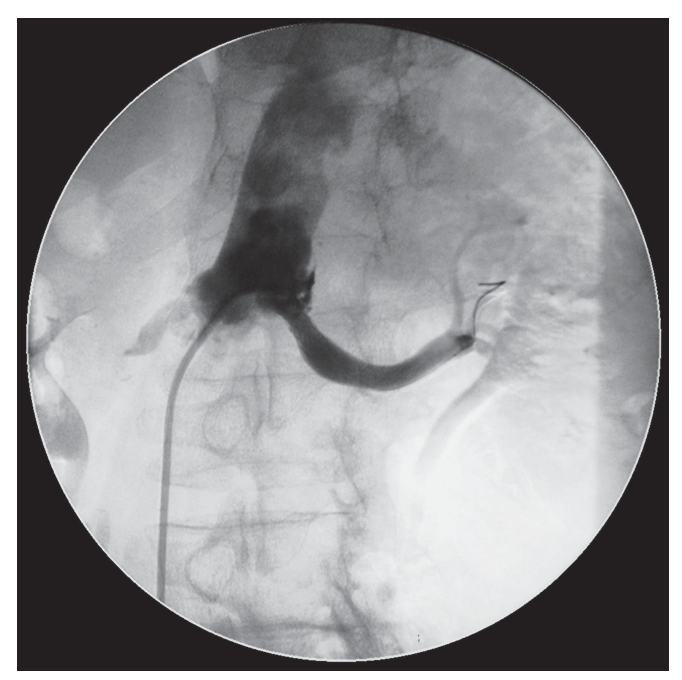

C

Fig. 2 A: Aortography reveals a severe stenosis in the ostium of the left renal artery. B: Predeployment selective angiography to confirm proper stent positioning. C: Completion angiography after angioplasty and stenting. 
実質性高血圧 , 糖尿病などを合併しているためと推測さ れる.一方 FMD に対する治療ではバルーン血管拡張術 により高率に降圧効果が得られることから ${ }^{27)}$, ステント 留置は解離などを生じた際の bail out use に限るべきと されている

腎機能についてはステント留置により改善されたとい う報告もあるが，多くは不変または悪化すると報告され ている28).

血管内治療における合併症発生頻度は 2-18\%，死亡率 は 0-2\%と報告されている28). 兴の内訳は, 穿刺部の出 血や血腫, カテーテルによる血管損傷 (穿孔, 解離, 閉 塞)，下肢末梢塞栓などである．20-30\%に腎機能の悪化 が見られるが , これは造影剤やカテーテル操作における 粥腫の末梢塞栓が主たる原因と考えられている．塞栓に 対してはフィルターなどのプロテクションデバイスの使 用が有効であるとの指摘がある ${ }^{29)}$.

\section{今後の展望}

血管内治療と薬物療法の比較では, 降圧効果におい て , 両者に差を認めなかったもの ${ }^{30)}$ と，血管内治療が有 効であったもの ${ }^{31}$ と異なる報告が存在する．また最近の

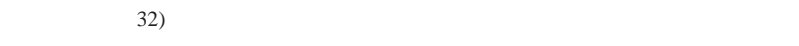
法との比較で腎機能改善や降圧効果などに有意差は認め られず，合併症の存在を考慮すると，臨床上の有益性は ないとする見解がある . これは今後の血管内治療の適応 を考慮する際に, 症例や病変の選択に十分注意が必要で あることを示唆している．

以上のように , 腎動脈狭窄に対する血管内治療につい ては，いまだ明確な゙治療指針がないのか現状であり，さ らなる大規模な study の蓄積が待たれるところである .

\section{文献}

1) Carrmeci C, Mc Clenathan J. Visceral artery aneurysm as seen in a community hospital. Am J Surg 2000; 179: 489-498.

2) Wagner WH, Allins AD, Treiman RL, et al. Ruptured visceral artery aneurysm. Ann Vasc surg 1997; 11: 342-347.

3) Messina LM, Shanley CJ. Visceral artery aneurysm. Surg Clin North Am 1997; 77 (2): 425-442.

4) Hossain A, Reis ED, Dave SP, et al. Visceral artery aneurysm: experience in a tertiary-care center. Am Surg 2001; 67: 432-437.

5) Stanley JC, Fry WJ. Pathogenesis and clinical significance of splenic artery aneurysm. Surgery 1974; 76: 898-909.

6) Holdsworth RJ, Gunn A. Ruptured splenic artery aneurysm in pregnancy: a review. Br J Obstet Gynaecol 1992; 99: 595-597.

7) Shanley CJ, Shah NL, Messina LM. Common splanchnic artery aneurysms: Splenic, hepatic and celiac. Ann Vasc Surg 1996; 10: 315-322.

8) Stone WM, Abbas M, Cherry KJ, et al. Superior mesenteric artery aneurysms: is presence an indication for intervention? $J$ Vasc Surg 2002; 36: 234-237.

9) Komori K, Mori E, Yamaoka T, et al. Successful resection of superior mesenteric artery aneurysm: a case report and review of the literature. J Cardiovasc Surg (Torino) 2000; 41: 475-478.

10) Obara H, Matsumoto K, Narimatsu $Y$, et al. Reconstractive surgery for segmental arterial mediolysis involving both the inter- nal carotid artery and visceral arteries. J Vasc Surg 2006; 43: 623-626.

11) Eckhauser FE, Stanley JC, Zelenock GB, et al. Gastroduodenal and pancreaticoduodenal artery aneurysms: a complication of pancreatitis causing spontaneous gastrointestinal hemorrhage. Surgery 1980; 88: 335-344.

12) Carr SC, Pearce WH, Vogelzang RL, et al. Current management of visceral artery aneurysm. Surgery 1996; 120: 627-634.

13) Hirsch AT, Haskal ZJ, Hertzer NR, et al. ACC/AHA 2005 guidelines for the management of patients with peripheral arterial disease (lower extremity, renal, mesenteric, and abdominal aortic): executive summary a collaborative report from the American Association for Vascular Surgery/Society for Vascular Surgery, Society for Cardiovascular Angiography and Interventions, Society for Vascular Medicine and Biology, Society of Interventional Radiology, and the ACC/AHA Task Force on Practice Guidelines (Writing Committee to Develop Guidelines for the Management of Patients With Peripheral Arterial Disease) endorsed by the American Association of Cardiovascular and Pulmonary Rehabilitation; National Heart, Lung, and Blood Institute; Society for Vascular Nursing; TransAtlantic Inter-Society Consensus; and Vascular Disease Foundation. $J$ Am Coll Cardiol 2006; 47: 1239-1312.

14) Rossi M, Rebonate A, Greco L, et al. Endovascular Exclusion of Visceral Artery aneurysms with Stent-Grafts: Technique and Long-Term Follow-up. Cardiovasc Interv Radiol 2008; 31: 3642.

15) Lagana D, Carrafiello G, Mangini M, et al. Multimodal approach to endovascular treatment of visceral artery aneurysms and pseudoaneurysms. Eur J Radiol 2006; 59: 104-111.

16) Tulsyan N, Kashyap VS, Greenberg RK, et al. The endovascular management of visceral artery aneurysms and pseudoaneurysms. J Vasc Surg 2007; 45: 276-283.

17) Guillon R, Garcier JM, Abergel A, et al. Management of splenic artery aneurysms and false aneurysms with endovascular treatment in 12 patients. Cardiovasc Interv Radiol 2003; 26: $256-260$.

18) Lupattelli T, Garaci FC, Sandhu C, et al. Endovascular treatment of a giant splenic aneurysm that developed after liver transplantation. Transpl Int 2003; 16: 756-760.

19) Brountzos EN, Vagenas K, Apostolopoulou SC, et al. Pancreatitis-associated splenic artery pseudoaneurysm: endovascular treatment with self-expandable stent-graft. Cardiovasc Interv Radiol 2003; 26: 88-91.

20) Sato N, Yamagichi K, Shimizu S, et al. Coil embolization of bleeding visceral pseudoaneurysms following pancreatectomy: the importance of early angiography. Arch Surg 1998; 133: 1099-1102.

21) Safian RD, Textor SC. Renal-artery stenosis. $N$ Engl J Med 2001; 344: 431-442.

22) Khosla $S$, White CJ, Collins TJ, et al. Effects of renal artery stent implamtation in patients with renovascular hypertension presenting with unstable angina or congestive heart failure. $A m$ J Cardiol 1997; 80: 363-366.

23) Conlon PJ, Athirakul K, Schwab SJ, et al. Survival in renal vascular disease. J Am Soc Nephrol 1998; 9: 252-256.

24) Van de Ven PJG, Kaatee R, Beutler JJ, et al. Arterial stentibg and balloon angioplasty in ostial atherosclerotic renovascular disease: randomized trial. Lancet 1999; 353: 282-286.

25) Cooper CJ, Murphy TP. The case for renal artery stenting for treatment of renal artery stenosis. Circulation 2007; 115: $263-$ 269.

26) Dworkin LD, Jamerson KA. Case against angioplasty and 
stenting of atherosclerotic renal artery stenosis. Circulation 2007; 115: 271-276.

27) Slovut DP, Olin JW. Fibromuscular dysplasia. $N$ Engl J Med 2004; 350: 1862-1871.

28) Edwards MS, Corriere MA. Contemporary management of atherosclerotic renovascular disease. J Vasc Surg 2009; 50: $1197-$ 1210.

29) Henry M, Benjelloun A, Henry I, et al. Renal angioplasty and stenting:is it still indicated after Astral and Star studies? J Cardiovasc Surg (Torino) 2009; 51: 701-720.

30) van Jaarsveld BC, Krijnen P, Pieterman H, et al. The effect of balloon angioplasty on hypertension in atherosclerotic renalartery stenosis. The Dutch Renal Artery Stenosis Intervention Cooperative Study Group. N Engl J Med 2000; 342: 1007-1014.

31) Nordmann AJ, Woo K, Parkes R, et al. Balloon angioplasty or medical therapy for hypertensive patients with atherosclerotic renal artery stenosis? A meta-analysis of randomized controlled trials. Am J Med 2003; 114: 44-55.

32) ASTRAL investigators, Wheatley K, Ives N, Gray R, et al. Revascularization versus medical therapy for renal artery stenosis. N Engl J Med 2009; 36: 1953-1962. 